\title{
Hermetic Storage Technology for Food Grains: New Beginning of Organic and Safe Storage for Farmers and Consumers: A Review
}

\author{
Vinod T. Atkari, Krantidip R. Pawar, Sujit C. Patil \\ Don Bosco College of Agriculture, Sulcorna, Quepem, Goa, India.
}

Received: May 2021

Accepted: December 2021

\begin{abstract}
The moisture content of grains, oxygen and carbon dioxide concentration in storage environment affects the storage life of food grains. The moisture content affects on storability of food grains severely, hence the storage structures must be provided with sufficient protection from moisture exchange between grain and atmosphere. The insect and pests grows very fast in presence of oxygen and moisture in the storage environment. The humid climate provides favorable conditions to moulds and insects to grow in most of the food grains and oilseeds. The grains exposed to these favorable environment further not useful for human consumptions. Many harmful chemicals like aflatoxins are formed in oilseeds and cereals. The emerging hermatic storage is highly effective technology to prevent the spoilage of grains without use of any harmful fumigants and chemicals, hence it is popularly known as organic storage technology. In this technology the flow of oxygen and water from external environment is fully controlled by impermeable, triple layer hermatic plastic bags.
\end{abstract}

Key words: Aflatoxins, Food grains, Hermatic bag, Hermetic storage, Organic storage technology.

ABBREVIATIONS: MT; Metric ton; RH: Relative humidity; HS: Hermatic storage; MC: Moisture content; LDPE: Low density polyethylene; PP: Polypropylene; FFA: Free fatty acids; IRRI: International rice research institute; PVC: Poly vinyl chloride; US: United States.

\section{Grain and Enemies \\ Grains biology}

The grain kernel is a living entity. Grain which is used for seed purpose must be kept alive and need to preserve their germination and reproduction properties. The germinative grains are preferred for food and feed purposes.

\section{Seed coat}

The seed coat covers the embryo and the endosperm (Fig 1). It protects the grain from attack by many insects. The seed coat cannot withstand attack of moulds and few insects. Those insects which attack the embryo are most dangerous because the seed coat in the area of the embryo is weak.

\section{Endosperm}

The $80 \%$ of the kernel volume make up by endosperm. It contains mostly starch and protein. Endosperm provides food for the developing seed when planted and food for the seed in storage. Also it provides food for humans and others if the grain is not being used as reproductive seed. Hence the endosperm needs to preserve during storage life.

\section{Embryo}

It is the part of the seed which can develop into a new plant. It contains most of the protein, fat and vitamins of the grain.
Insects and moulds easily attack on embryo. Seed grain which is attacked will not grow properly. Food grains without embryos do not provide as much nutrition as grains with embryos. Hence embryos need to preserve during storage of grains.

\section{Life activity-respiration of grain}

Respiration of grain produces heat, water and carbon dioxide (Fig 2). This process consumes dry matter from the grain. Heat and carbon dioxide are formed by the activity of bacteria, fungi and insects. Heat and water resulting from the respiration of the grain as well as the activity of bacteria, fungi and insects cause an increase in moisture content and temperature, which again increases the life activity in grains and finally grains are spoiled very fast. As germinative grains breathes. Each kernel gets oxygen from the air and burns food from its endosperm. This process gives off heat, water and carbon dioxide. In many countries, respiration during the storage period is causing a dry matter loss of $1 \%$ or more. The $1 \%$ dry matter loss in 1 ton grain produces $37,600 \mathrm{kcal}$ energy and increasing temperature by $65^{\circ} \mathrm{C}$, if heat is not transmitted (Hall, 1970).

\section{Enemies of grain}

The water and heat produced by respiration activity are harmful to grains. The real damage to the grain is caused by fungi, insects and mites which thrive under warm and

\footnotetext{
${ }^{*}$ Corresponding author's E-mail: ervinodatkari@gmail.com

1Don Bosco College of Agriculture, Sulcorna, Quepem, Goa, India.

${ }^{2}$ Dr. D.Y. Patil, College of Agricultural Engineering and Technology, Talsande, Kolhapur-416 112, Maharashtra, India.

${ }^{3}$ Grain Pro India Post Harvest Technology Pvt Ltd.
} 
humid conditions. Hence grains needs to be stored and handled properly (Anonymous, 2014).

\section{Fungi}

Fungi are small plants without roots, leaves and chlorophyll; they live on other materials like grains. Fungi reproduced by small airborne spores which are spread everywhere by the wind. There are two basic types: field fungi and storage fungi. Field fungi deteriorate wet crop in the field but die as soon as the grain is brought to the storage after harvesting. Storage fungi are found everywhere on farms, grain handling equipments, grain stores, etc. Fungi not only destroy germinative property but also produce dangerous toxins; these fungi will be controlled by drying of grains to the safe moisture content of less than $10-12 \%$.

\section{Insects}

The insects attack grains in warm and humid climates very easily. High moisture content grains and storage environment having temperature between 28 to $38^{\circ} \mathrm{C}$, makes the kernels soft and vulnerable to attack by insects. This soft grains provide an ideal food mixture of dry matter and water for insects to thrive on, each female can produce up to 400 eggs within a couple of months. The insects and their larvae can consume considerable amounts of dry matter and seriously spoil germination capacity of grains. The grains attacked by insects are with their holes left completely open to attacks by fungi. Hence, lower the moisture content and the storage temperature, the problem of insects will be restricted. It can be easily achieved in hermatic grain storage. In hermatic storage the insects, eggs and larvae are destroyed due to very low level of oxygen (Fig 9) and high level of $\mathrm{CO}_{2}$.

\section{Mites}

There are more than 80 species of grain mites are known, these have never received the same attention as e.g., insects, because they are more difficult to see and they eat less grain than insects. Especially in temperate climates mites are a serious pest. The best way to control mites is to dry the grain to $13-14 \%$ M.C. and maintain the same M.C. during storage which can be easily achieved by low cost hermetic storage.

\section{Hermatic storage}

The success of grain storage technology depends on controlling the relevant critical level oxygen availability, temperature and grain moisture content.

In maize, rice, peanuts, nuts and dried fruits the Aflatoxins (Aspergillus flavus and Aspergillus parasiticus) is a major problem, especially in hot, humid climates. Aflatoxin producing molds grow exponentially in conventional multi-month storage like godowns due to higher temperature and humidity (Hell et al., 2010).

As per the research conducted by IRRI, brown rice has a very short shelf life, because Aflatoxin and FFA development is a very serious problem in brown rice storage.

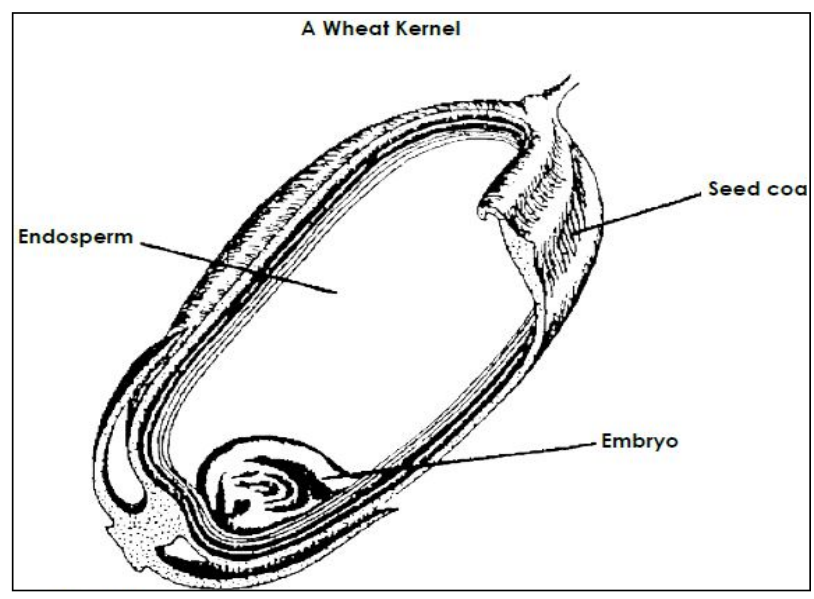

Fig 1: Grain biology.

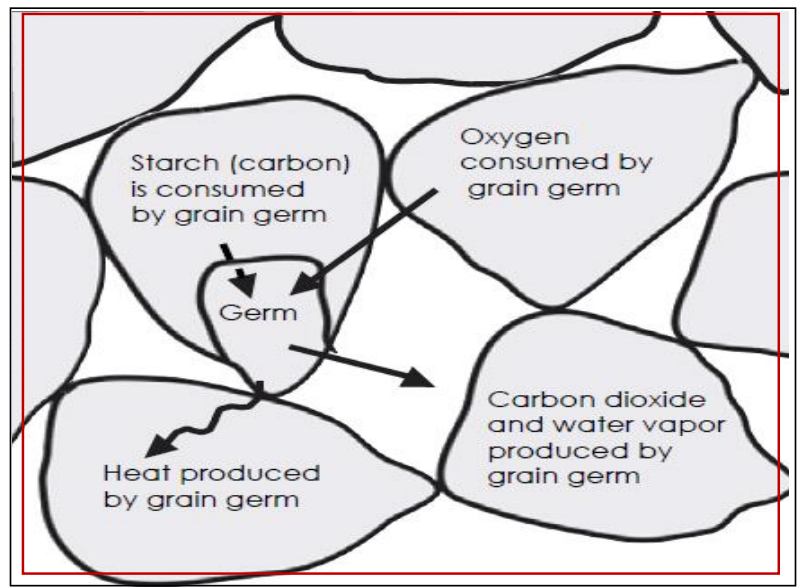

Fig 2: Respiration of grain.

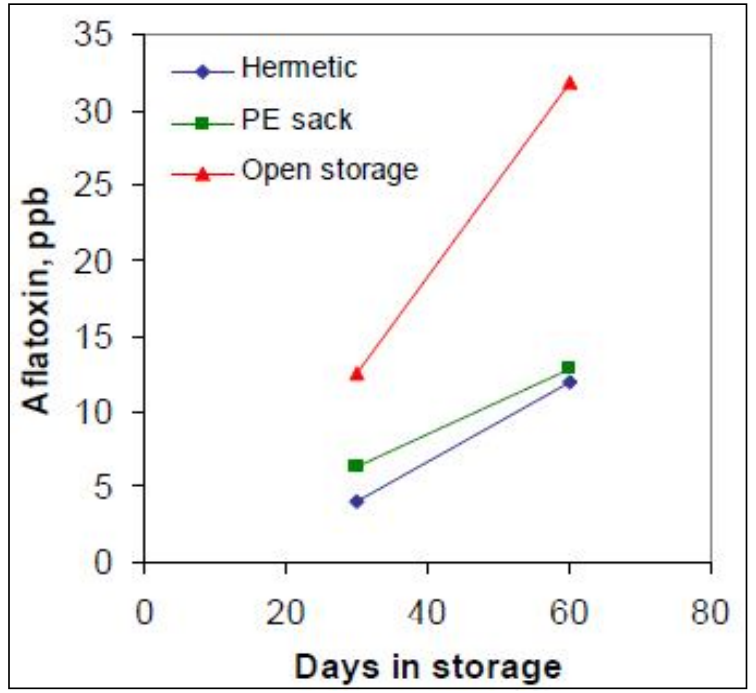

Fig 3: Hermatic and normal plastic bags storage- Aflatoxin levels in brown rice.

(Source: Martin G. and Chris C. 2013. The International Rice Research institute). 
The Super bag (hermatic storage) has very promising results in controlling the aflatoxin development as shown in Fig 3.

\section{Hermatic bags}

The hermatic bags are a triple layer plastic bags that serves as an air tight (hermatic) way for storage (Fig 4). Triple layer is composed of two inner bags of low density polyethylene (LDPE) fitted inside and outer sack composed of woven polypropylene (PP). The inner LDPE liners are composed of wall thickness of 80 microns. They greatly hinder the movement of oxygen across the wall of the bag. The tough outer woven enables easy handling of bag and gives better life.

\section{Steps in using bags}

Step 1: Make sure that the grains are properly dried to safe moisture content ( $<14 \% \mathrm{MC})$. Place hermatic bag inside another bag of jute or polypropylene (Fig 5).

Step 2: Fill the hermatic bag with dried seeds or grains.

Step 3: Remove the air from the bag completely. To remove air, press from the side of the bags to expel out air from the bag. Then twist the free plastic to fold it two times (Fig 6).

Step 4: Tie off the twist with a strong rubber band or an adhesive tape (Fig 7).

Step 5: Close the outer bag by tying or sewing. Make sure not to puncture the hermatic bag, pull the middle bag up over the first one so that it completely surrounds it. Twist the lip shut, fold over and tie, as before. Follow the same step for the outer woven bag (Fig 8).

Precausion when using the bags: Make sure the following points.

a) Do not over fill the hermatic bags.

b) Do not puncture or damage the bag.

c) Never carry the grain by holding on to the hermatic bag, always use the outer bag for carrying.

d) Seal the bag properly.

e) Do not use hooks to hang the bags.

f) Clean, dry, fold bags (undamaged hermatic bags can be resued).

g) Check regularly for leaks and reseal it.

\section{Different forms of hermatic storage}

Nowadays hermetic storage systems are used in all parts of world for storage of high and medium value commodities. Hermetic storage has three distinct forms:

\section{Organic-hermetic storage}

The hermetic storage is widely used for storing the commodities like maize, wheat, rice, pulses both at farm, and at cluster level. At domestic level house ladies facing problems of infestations in split pulses (dal) and in whole grains. To avoid use of hazardous fumigants, boric acids powder for protecting these products, HS is very effective and economical option for fewer capacities too.

The organic hermatic storage method creates a low oxygen modified atmosphere which normally results in $100 \%$ insect mortality of all life stages and prevent mold development in a few days. It also prevents development of cancer causing mycotoxins such as aflatoxins and ochratoxin A (OTA). The low permeability of the hermetic structure also maintains safe constant moisture levels in previously dried commodities regardless of ambient exterior temperature and humidity. Hence it is very useful for protecting grains in high humidity coastal areas.

In storage of rice bran, brown rice, peanuts and cocoa beans the quality loss due to increase in Free Fatty Acids (FFAs) are prevented through a low oxygen environment

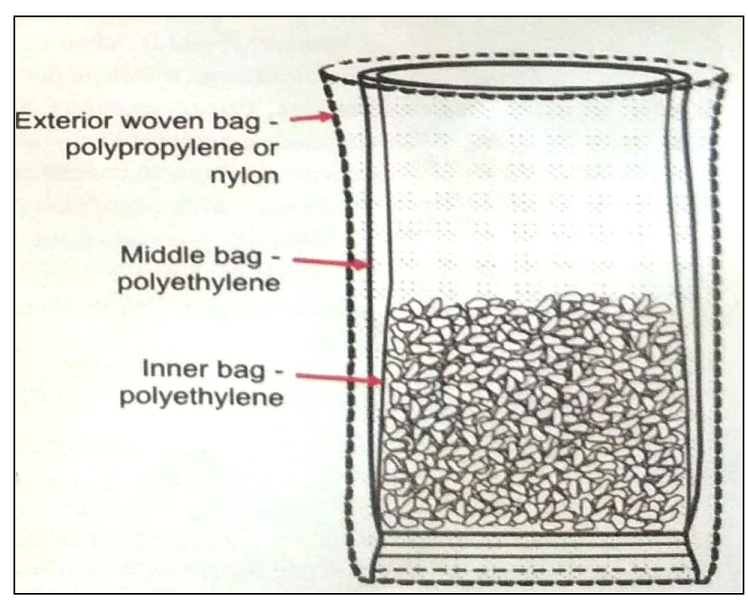

Fig 4: Hermatic bag.

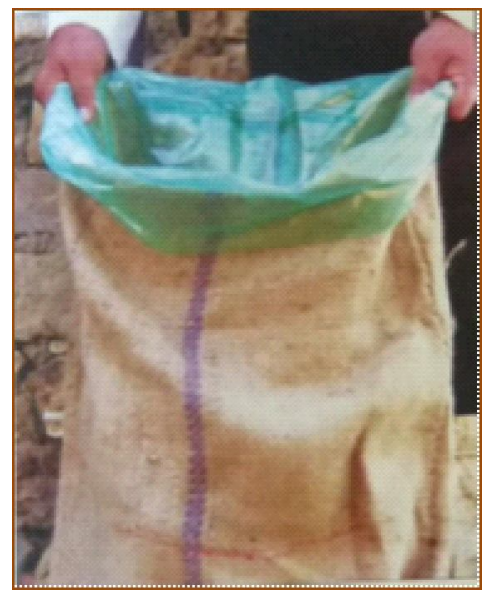

Fig 5: Hermatic bag inside jute bag.

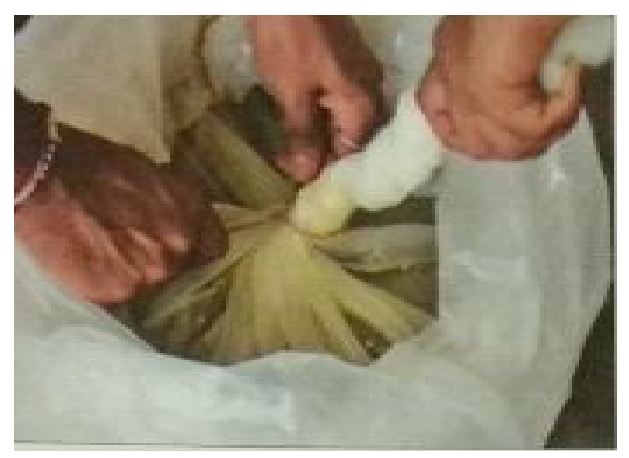

Fig 6: Air removing by twisting. 
without use of harmful fumigants (De Bruin and Murali, 2006; Finkelmann et al., 2003; Montemayor, 2004).

\section{Vacuum-hermetic fumigation}

In this storage a vacuum pump is used to create a very low pressure atmosphere for accelerated dis-infestation of noncrushable commodities through asphyxiation.

\section{Gas- hermetic fumigation}

In this type of storage gas is supplied from outside (usually $\mathrm{CO}_{2}$ ). A super grain bags is a recent and popular transportable form of hermetic storage. The International Rice Research Institute (IRRI), Philippines utilizes a thin, transparent, extremely low permeability co-extruded multi layer plastic as a liner to a conventional jute or polypropylene bag. Most hermetic storage systems made from flexible food grade PVC which is lightweight and portable when empty. With Super Grain bags the hermetic storage became possible during transport and subsequent distribution. This type of storage technology are widely used for coffee and cocoa beans (Villers et al., 2006).

\section{Storage of coffee beans and peanuts}

FFA (Free fatty acids), mold and aflatoxins developments are the major factors responsible for the spoilage in peanut storage. Recently the use of hermetic storage has been extended to the storage of peanuts as it controls all factors

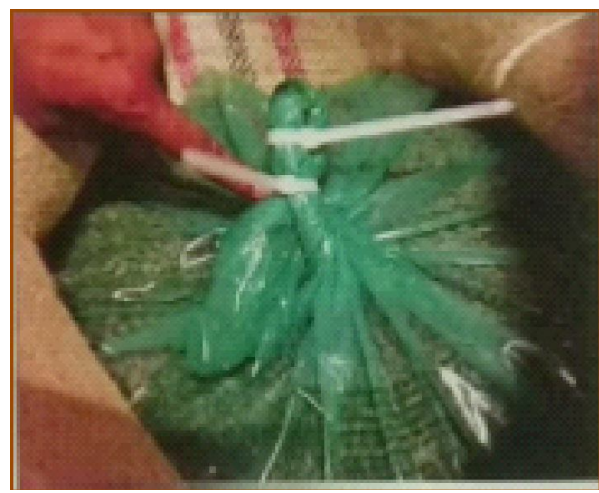

Fig 7: Teing with strong rubber band or by adhesive tape.

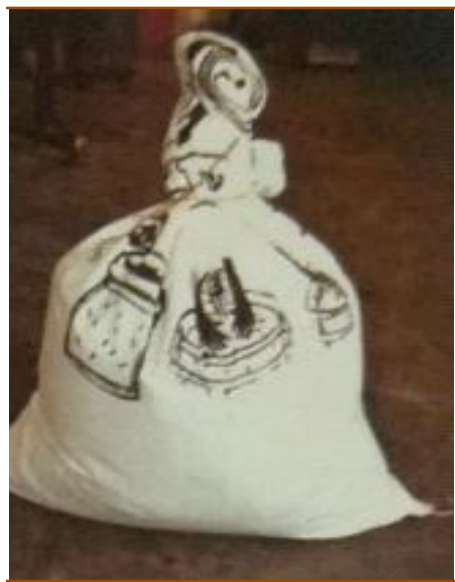

Fig 8: Outer bag tying or sewing. very effectively. In hot and humid climates the coffee beans and peanuts are stored for longer duration without any hazard to quality, aroma and taste.

\section{Storage of rice and rice products}

Asia is become largest user of hermetic storage because of its use for safe storage of rice seeds and different rice products. Rice stored in hot-humid climates has a high degree of insect infestation, problems with rodents and quality issues with respect to taste, aroma and appearance after 6 months of storage life. In experiments made at IRRI, Philippines for milled rice storage in hermatic bags, it can be safely kept for more than one year (Rickman and Aquino,

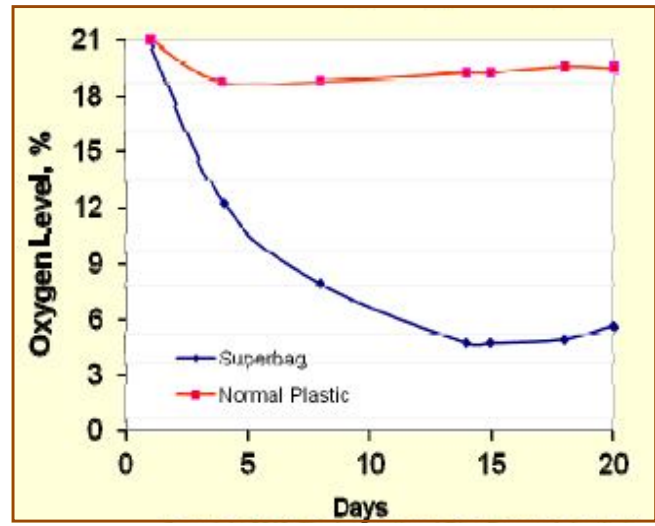

Fig 9: Hermatic and normal plastic bags storage Oxygen level during storage

(Source: Martin G. and Chris C. 2013).

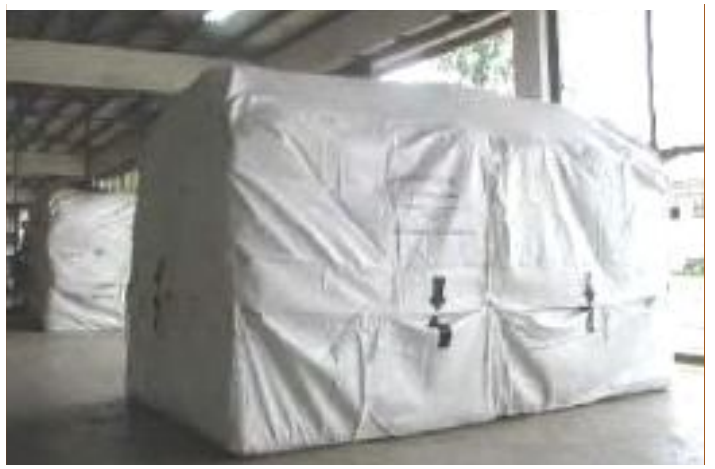

Fig 10: Five ton cocoon.

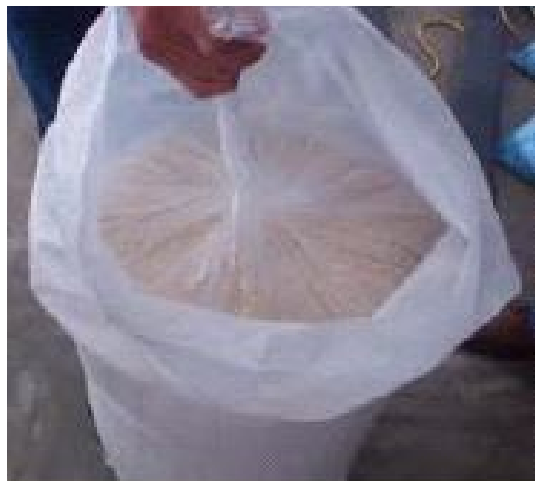

Fig 11: Fifty kg super bag. 
2003; 2004). The milling rates obtained will be higher from rice stored in hermatic storage as compare to normal storage (Montemayor, 2004).

\section{Hermetic storage for seeds}

Hermetic storage of seeds followed since 1990, extensive research on storage of rice seeds was carried out by the International Rice Research Institute (IRRI) in the Philippines (Rickmann and Aquino, 2003; 2004). The cocoons (Fig 10) which a flexible hermatic storage is widely used to store all types of seeds. The Super grain bags which is a portable hermetic storage solution (Fig 11) used as liners to conventional bags upto $50 \mathrm{~kg}$ capacity. The hermetic technique for maintaining seeds has around same results to more expensive refrigeration processes in maintaining a high level of germination and vigor.

The further insects development in storage of seeds is prevented, by creating low level of oxygen, high level $\mathrm{CO}_{2}$ atmosphere lethal to insects already present inside the container. It is also used to prevent rodent penetration during storage and prevent the growth of molds as well as deterioration of the commodity by protecting it from the high outside relative humidity levels that prevail in hot humid climates (De Bruin, 2005).

\section{Alternatives to hermetic storage}

Alternatives to hermetic storage may be the use of chemical fumigants, refrigeration, freezing, conventional godowns and silos. Fumigants penetrate into the commodity is often a problem, repeated applications are frequently required and also fumigants do not prevent losses from rodents or the growth of molds. The insects have developed tolerance to widely used fumigants, the most effective Methyl Bromide is being phased out by regulatory bodies. Refrigeration, in the case of seeds, remains widely used, but it consumes significant energy, requires special facilities which will increase the cost of storage and handling. Most of the organization still uses conventional storages, such as storage of bagged grains under large tin roofs in open warehouses. In conventional godown storage huge amount of grains are lost from rodents, insects and mold. In hot and humid climates grain losses are about 12.5 to 25\% (Minagri, 2006). Hermetic storage as compared to conventional storage processes is still relatively new its use is now continuously increasing.

\section{Future prospectus}

Pesticide free hermetic storage technology has already been found suitable for grains. This is especially true where conventional storage and modern silo storage in hot - humid climates, fails to adequately protect the stored commodity for the desired time and this results in large losses in quantity and quality. Hermetic storage is sustainable; it is user friendly and an environmentally green technology that does not necessitate the use of chemical pesticides. This technology can be adapted to the protection of commodities both at farmers and consumers level in any sizes ranging from few kilograms to thousands of tonnes. It is cost effective, environment friendly, easiest technology.

\section{REFERENCES}

Anonymous. (2014). Grain Bilogy. Kongskilde Industries A/S.

De Bruin, T. (2005). Seeds in Store. Asian Seed and Planting Material, February.

De Bruin, T., Murali, V. (2006). Quality Preservation of Stored Cocoa Beans in the Tropics. (unpublished). Grain Pro Document Number SL2299TB0905. GrainPro, Inc. Concord, MA USA.

Finkelman, S., Navarro, S., Isikber, A., Dias, R., Azrieli, A., Rindner, M., Lotan, Y., De Bruin, T. (2003). Insects control of cocoa pests using a novel vacuum approach. IWCSPP, CAB International, Oxon, UK, pp. 579-582.

Hell, K., Mutegi, C., Fandohan, P. (2010). Aflatoxin control and prevention strategies in maize for Sub-Saharan Africa, in $10^{\text {th }}$ International Working Conference on stored Product Protection, Green. J. Agril. Sci. 2: 534-540.

Minagri (Rwandan Ministry of Agriculture), (2006). Systeme de Stockage Hermetique au Rwanda: 36 mois d'experience. Minagri. Kigali, Rwanda.

Montemayor, R. (2004). Better Rice in Store. World Grain, November.

Rickman, J.F., Aquino, E. (2003). Hermetically Sealed Grain Storage Systems. (unpublished), IRRI, Philippines, GrainPro Document Number SL2258PV0803, GrainPro, Inc. Concord, MA USA.

Rickman, J.F., Aquino, E. (2004). Appropriate Technology for Maintaining Grain Quality in Small-scale Storages. CAF 2004 International Conference on Controlled Fumigation in Stored Products 8-13 August 2004 Gold Coast, Australia.

Villers, P., de Bruin, T. and Navarro, S. (2006). Development and applications of the hermetic storage technology. GrainPro, Inc., 200 Baker Ave., Suite 309, Concord, MA 01742. 